\title{
Materiały do bioty porostów Nadleśnictwa Doświadczalnego Zielonka w Wielkopolsce
}

\author{
Rafae Szymczyk, Monika Konatowska i Pawe€ RutKowski
}

\begin{abstract}
Szymczyk, R., Konatowska, M. And Rutkowski, P. 2020. Contribution to the lichen biota of the Zielonka Experimental Forest Division (Wielkopolska Province, Poland). Fragmenta Floristica et Geobotanica Polonica 27(2): 297-311. Kraków. e-ISSN 2449-8890, ISSN 1640-629X.

ABSTRACT: This paper presents the results of lichenological studies carried out in the Zielonka Forest near Poznań, which yielded new information about the lichens of that forest. A total of 81 taxa were found in the area, of which 5 are legally protected and 18 are considered endangered in Poland. Agonimia flabelliformis, A. repleta, Bacidina mendax and Parmelia serrana are new for the Pojezierze Wielkopolskie lakeland. The biota includes such valuable species as Arthonia mediella, Chaenotheca chlorella, Chrysothrix candelaris, Microcalicium disseminatum, Punctelia subrudecta and Toniniopsis subincompta.
\end{abstract}

\begin{abstract}
KEY WORDS: Ascomycota, lichenized fungi, rare species, threatened and protected species, Zielonka Forest

R. Szymczyk (autor korespondencyjny), Pracownia Ekspertyz Przyrodniczych EKOPROJEKT, Nowica 24, 14-405 Wilczęta, Polska; e-mail: graphis22@poczta.onet.pl

M. Konatowska, P. Rutkowski, Katedra Siedliskoznawstwa i Ekologii Lasu, Uniwersytet Przyrodniczy w Poznaniu, ul. Wojska Polskiego 71F, 60-625 Poznań, Polska
\end{abstract}

\section{WSTĘP}

Nadleśnictwo Doświadczalne Zielonka, jako obiekt naukowo-dydaktyczny, zostało powołane w 1925 r., a w 1927 r. opracowano dla niego pierwszy operat urządzenia lasu. W 1947 r., na podstawie aktu porozumienia między Ministerstwem Leśnictwa a Uniwersytetem Poznańskim, obszar ostatecznie został przeznaczony na cele naukowe (KoNATOwsKA \& RutKowski 2011; NAdleśnictwo 2020). Ten fragment Puszczy Zielonki posiada bogato udokumentowany stan wiedzy na temat środowiska naturalnego. W latach 50. ubiegłego wieku szczegółowo opisano zbiorowiska roślinne, występowanie cennych gatunków roślin oraz scharakteryzowano florę mszaków (NowACZYK 1955, 1959, 1960, 1964). Porostom Nadleśnictwa Doświadczalnego Zielonka nie poświęcano w tym czasie szczególnej uwagi. W starszych pracach dotyczących grzybów zlichenizowanych na obszarze Wielkopolski możemy znaleźć szczątkowe informacje z tego terenu (KRAwIEC 1934, 1935, 1938; DzIABASZEWSKI 1959, 1962). Uwagę na ten obszar zwrócił dopiero Kazimierz Glanc publikując pierwsze prace dotyczące zielnika porostów Doświadczalnego Nadleśnictwa Zielonka 
(GLANC 1956, 1957, 1961). W późniejszych latach ukazały się dwie kolejne, obszerne prace tego autora, dotyczące ugrupowań porostów epifitycznych oraz bioty porostów w zespołach leśnych Puszczy Zielonki (Glanc 1965, 1967). Teren ten na wiele lat stał się głównym obiektem badawczym Glanca, a w rezultacie powstały artykuły podsumowujące jego wieloletnie obserwacje (GLANC 1995, 1998).

W najnowszej literaturze dotyczącej Puszczy Zielonki prezentowane są wyniki licznych badań z zakresu ekologii lasu z wykorzystaniem najnowocześniejszych metod badawczych (RUTKOWSKI \& ŚMIGIELSKA-WOJTYNIAK 2008; RATYŃSKA i in. 2015; KONATOWSKA \& RUTKOWSKI 2019; RUTKOWSKI i in. 2019; TURCZAŃSKI i in. 2020). Brakuje jednak nowych publikacji opisujących porosty tego obszaru. Nieliczne opublikowane prace dotyczą jedynie pojedynczych gatunków z wybranych grup systematycznych (CZARNOTA 2007; KuKWA 2006, 2011; KOWALEWSKA i in. 2008; JABŁOŃSKA 2012; WIECZOREK 2018).

Celem przeprowadzonych badań było poznanie zróżnicowania gatunkowego porostów na obszarze oddziału leśnego nr 73 Nadleśnictwa Doświadczalnego Zielonka. Uzyskane wyniki są uzupełnieniem wiedzy na temat porostów Puszczy Zielonki i Wielkopolski.

\section{TEREN BADAŃ}

Nadleśnictwo Doświadczalne Zielonka zajmuje powierzchnię 4567 ha. Badania zostały przeprowadzone w granicach oddziału 73 zajmującego obszar 40 ha. Oddział ten stanowi stałą powierzchnię badawczą Katedry Siedliskoznawstwa i Ekologii Lasu (Uniwersytet Przyrodniczy w Poznaniu, Wydział Leśny).

Zgodnie z regionalizacją przyrodniczo-leśną Polski (ZIELONY \& KLICZKOwsKA 2012) oddział 73 położony jest w Krainie Wielkopolsko-Pomorskiej, mezoregionie Pojezierzy Wielkopolskich. Według podziału fizycznogeograficznego (KoNDRACKI 2009) obszar objęty opracowaniem wchodzi w skład Pojezierza Gnieźnieńskiego. Oddział 73, podobnie jak całe Nadleśnictwo Doświadczalne Zielonka, stanowi także część Parku Krajobrazowego Puszcza Zielonka.

Wielkopolska, w obrębie której położona jest powierzchnia badawcza, jako region geograficzny, uważana jest za jeden z najsuchszych obszarów Polski. Wynika to głównie z niskiej rocznej sumy opadów atmosferycznych. Dla stacji meteorologicznej Zielonka (5 km na północny wschód od obszaru badań), za lata 1986-2008 wynosiła ona średnio $525 \mathrm{~mm}$ rocznie. Chociaż linia trendu opadów jest względnie stała, suma roczna opadów różni się znacznie w poszczególnych latach (od 312 mm w 1989 r. do 724 mm w 1993 r.) (RUTKOWSKI i in. 2019). Średnia roczna temperatura powietrza, według tego samego źródła i za ten sam okres, wynosiła $8,3^{\circ} \mathrm{C}$. Na powierzchni badawczej, pokrytej drzewostanem, warunki termiczne i wilgotnościowe moga być nieco inne. Jak wykazały dane pozyskane $\mathrm{z}$ rejestratora umieszczonego na stanowisku nr 3 (Ryc. 1), $2 \mathrm{~m}$ nad poziomem gruntu, średnia roczna temperatura w 2019 r. wyniosła $10,2^{\circ} \mathrm{C}$, natomiast przeciętna wilgotność powietrza $88 \%$.

Teren oddziału 73 jest lekko pofalowany. Obejmuje pagórki polodowcowe pokryte utworami piaszczysto-glinowymi, z których wykształciły się głównie gleby rdzawe brunatne, 


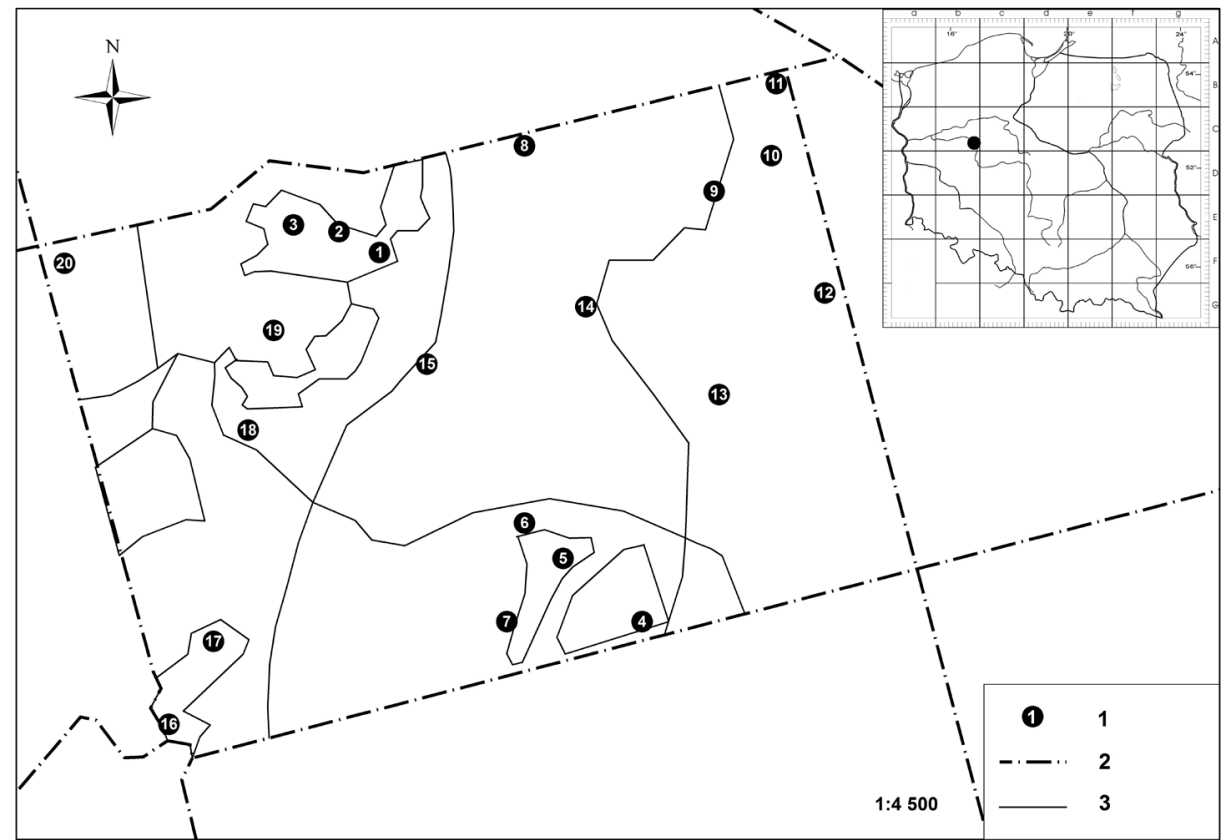

Ryc. 1. Lokalizacja stanowisk na terenie oddziału nr 73. 1 - powierzchnie badawcze, 2 - granica oddziałów, 3 - granica wydzieleń

Fig. 1. Location of investigated sites in forest unit 73. 1 - research plots, 2 - forest unit border, 3 - forest section border

miejscami przechodzące w płowe brunatne oraz zagłębienia terenu wypełnione utworami organicznymi (głównie torfami niskimi, miejscami podścielonymi gytią wapienną). Obszar ten porośnięty jest prawie wyłącznie przez grąd środkowoeuropejski Galio sylvaticiCarpinetum betuli, o różnym stopniu przekształcenia (por. Tab. 1). Są to głównie drzewostany dębowe w wieku od 150 do 175 lat. Domieszkę stanowi Pinus sylvestris w podobnym wieku. Drugie piętro drzewostanu tworzy na ogół Carpinus betulus, przeważnie w wieku 70-75 lat. W północno-zachodniej części oddziału, w obniżeniach terenu, zlokalizowane są niewielkie powierzchnie olsu porzeczkowego Ribeso nigri-Alnetum, z Alnus glutinosa w wieku 55 do 70 lat. Najmniejszą powierzchnię zajmuje łęg jesionowo-olszowy Fraxino-Alnetum, który leży w zachodnio-południowej części oddziału. Na tej powierzchni drzewostan osiagga wiek 105 lat (RUTKOwsKi 2002; BULiGL 2014). Z uwagi na znaczenie naukowo-dydaktyczne, drzewostany w całym oddziale 73 zostały wyłączone z użytkowania na początku lat $70 . \mathrm{XX}$ wieku.

\section{MATERIAŁ I METODY}

Badania terenowe wykonano w 2019 r. Obserwacje przeprowadzono na 20 stanowiskach (Ryc. 1), o powierzchni około 0,25 ha każda. W trakcie prac penetrowano wszystkie dostępne dla porostów siedliska. Porosty, których identyfikacja była możliwa w terenie, spisywano. W przypadku pozostałych gatunków zbierano okazy do dalszych analiz. Zebrany materiał zielnikowy zdeponowano w Herbarium 
Tabela 1. Charakterystyka stanowisk badawczych położonych w oddziale 73

Table 1. Characteristics of research localities in forest unit 73

\begin{tabular}{|c|c|c|c|c|c|}
\hline \multirow{2}{*}{$\begin{array}{c}\text { Stano- } \\
\text { wisko } \\
\text { (Locality) }\end{array}$} & \multirow{2}{*}{$\begin{array}{l}\text { Oddział } \\
\text { leśny } \\
\text { (Forest } \\
\text { section) }\end{array}$} & \multicolumn{2}{|c|}{ Współrzędne (Coordinates) } & \multirow{2}{*}{$\begin{array}{l}\text { Typ zbiorowiska } \\
\text { (Type of plant } \\
\text { association) }\end{array}$} & \multirow{2}{*}{$\begin{array}{l}\text { Drzewostan: gatunek - wiek } \\
\text { (Tree stand: species - age) }\end{array}$} \\
\hline & & $\mathrm{N}$ & $\mathrm{E}$ & & \\
\hline 1 & $73-d$ & $52^{\circ} 31^{\prime} 32,1^{\prime \prime}$ & $17^{\circ} 03^{\prime} 09,2^{\prime \prime}$ & $\mathrm{Rn}-\mathrm{A}$ & $A-55$ \\
\hline 2 & 73-d & $52^{\circ} 31^{\prime} 32,8^{\prime \prime}$ & $17^{\circ} 03^{\prime} 07,0^{\prime \prime}$ & $\mathrm{Rn}-\mathrm{A}$ & $A-55$ \\
\hline 3 & $73-d$ & $52^{\circ} 31^{\prime} 32,9^{\prime \prime}$ & $17^{\circ} 03^{\prime} 04,6^{\prime \prime}$ & $\mathrm{Rn}-\mathrm{A}$ & $A-55$ \\
\hline 4 & 73-1 & $52^{\circ} 31^{\prime} 20,2^{\prime \prime}$ & $17^{\circ} 03^{\prime} 23,9^{\prime \prime}$ & Gs-Cb & $\begin{array}{l}Q, P-176 \\
F-55,85 \\
Q-55,85\end{array}$ \\
\hline 5 & 73-m & $52^{\circ} 31^{\prime} 22,2^{\prime \prime}$ & $17^{\circ} 03^{\prime} 19,5^{\prime \prime}$ & $\mathrm{T}$ & $S-20$ \\
\hline 6 & 73-n & $52^{\circ} 31^{\prime} 23,4^{\prime \prime}$ & $17^{\circ} 03^{\prime} 17,4^{\prime \prime}$ & Gs-Cb & $\begin{array}{l}\mathrm{Q}, \mathrm{P}-170 \\
\mathrm{Q}, \mathrm{C}, \mathrm{F}-75\end{array}$ \\
\hline 7 & $73-n$ & $52^{\circ} 31^{\prime} 20,1^{\prime \prime}$ & $17^{\circ} 03^{\prime} 16,6^{\prime \prime}$ & Gs-Cb & $\begin{array}{l}\mathrm{Q}, \mathrm{P}-170 \\
\mathrm{Q}, \mathrm{C}, \mathrm{F}-75\end{array}$ \\
\hline 8 & 73-b & $52^{\circ} 31^{\prime} 35,7^{\prime \prime}$ & $17^{\circ} 03^{\prime} 16,9^{\prime \prime}$ & Gs-Cb & $\begin{array}{l}Q-156 \\
P-175 \\
Q, C-75\end{array}$ \\
\hline 9 & 73-b & $52^{\circ} 31^{\prime} 34,4^{\prime \prime}$ & $17^{\circ} 03^{\prime} 27,1^{\prime \prime}$ & Gs-Cb & $\begin{array}{l}Q-156 \\
P-175 \\
Q, C-75\end{array}$ \\
\hline 10 & 73-a & $52^{\circ} 31^{\prime} 35,6^{\prime \prime}$ & $17^{\circ} 03^{\prime} 30,2^{\prime \prime}$ & Gs-Cb & $Q-150, C-45$ \\
\hline 11 & $73-\mathrm{a}$ & $52^{\circ} 31^{\prime} 38,0^{\prime \prime}$ & $17^{\circ} 03^{\prime} 30,3^{\prime \prime}$ & Gs-Cb & $Q-150, C-45$ \\
\hline 12 & 73-a & $52^{\circ} 31^{\prime} 31,2^{\prime \prime}$ & $17^{\circ} 03^{\prime} 33,2^{\prime \prime}$ & $\mathrm{Gs}-\mathrm{Cb}$ & $Q-150, C-45$ \\
\hline 13 & $73-\mathrm{a}$ & $52^{\circ} 31^{\prime} 27,7^{\prime \prime}$ & $17^{\circ} 03^{\prime} 27,7^{\prime \prime}$ & Gs-Cb & $Q-150, C-45$ \\
\hline 14 & 73-b & $52^{\circ} 31^{\prime} 30,5^{\prime \prime}$ & $17^{\circ} 03^{\prime} 20,4^{\prime \prime}$ & Gs- $\mathrm{Cb}$ & $\begin{array}{l}Q-156 \\
\mathrm{P}-175 \\
\mathrm{Q}, \mathrm{C}-75\end{array}$ \\
\hline 15 & $73-b$ & $52^{\circ} 31^{\prime} 28,5^{\prime \prime}$ & $17^{\circ} 03^{\prime} 11,9^{\prime \prime}$ & Gs-Cb & $\begin{array}{l}Q-156 \\
P-175 \\
Q, C-75\end{array}$ \\
\hline 16 & 73-p & $52^{\circ} 31^{\prime} 16,4^{\prime \prime}$ & $17^{\circ} 02^{\prime} 58,6^{\prime \prime}$ & F-A & A -105 \\
\hline 17 & 73-p & $52^{\circ} 31^{\prime} 19,2^{\prime \prime}$ & $17^{\circ} 03^{\prime} 00,9^{\prime \prime}$ & F-A & $A-105$ \\
\hline 18 & $73-c$ & $52^{\circ} 31^{\prime} 26,2^{\prime \prime}$ & $17^{\circ} 03^{\prime} 02,4^{\prime \prime}$ & Gs-Cb & $\begin{array}{l}Q-156 \\
P-175 \\
Q-130 \\
C-75\end{array}$ \\
\hline 19 & $73-\mathrm{g}$ & $52^{\circ} 31^{\prime} 29,5^{\prime \prime}$ & $17^{\circ} 03^{\prime} 03,7^{\prime \prime}$ & Gs-Cb & $\begin{array}{l}\mathrm{Q}, \mathrm{P}-170 \\
\mathrm{Q}, \mathrm{C}-130\end{array}$ \\
\hline 20 & 73-h & $52^{\circ} 31^{\prime} 31,5^{\prime \prime}$ & $17^{\circ} 02^{\prime} 52,3^{\prime \prime}$ & Gs-Cb & $\begin{array}{l}\mathrm{Q}, \mathrm{P}-160 \\
\mathrm{Q}, \mathrm{C}-75\end{array}$ \\
\hline
\end{tabular}

Objaśnienia (Explanations): A - Alnus glutinosa, F - Fagus sylvatica, C - Carpinus betulus, $\mathrm{P}$ - Pinus sylvestris, $\mathrm{Q}$ - Quercus petraea, S - Salix sp., F-A - Fraxino-Alnetum, Gs-Cb - Galio sylvatici-Carpinetum betuli, Rn-A - Ribeso nigri-Alnetum, T - turzycowisko (sedge field). 
Katedry Taksonomii Roślin i Ochrony Przyrody Uniwersytetu Gdańskiego (UGDA). Skład wtórnych metabolitów porostowych badano za pomocą chromatografii cienkowarstwowej TLC (por. ORANGE i in. 2001; KuBIAK \& KuKWA 2011).

Nazewnictwo taksonów przyjęto za FAŁTYNOwiCZEM i KossowsKą (2016) z wyjątkiem gatunków Bacidina mendax (CZARNOTA \& GUZOW-KRZEMIŃSKA 2018), Lepra amara (HAFELLNER \& TÜRK 2016) i Toniniopsis subincompta (KISTENICH i in. 2018). Nazwy w wykazie gatunków ułożono w kolejności alfabetycznej. Przy każdym taksonie podano rodzaje substratów oraz numery stanowisk. Dla porostów ginących w Polsce podano odpowiednie kategorie ich zagrożenia (CIEŚLIŃSKI i in. 2006). W pracy zastosowano następujące skróty: stan. - stanowisko, OS - ochrona ścisła, OC - ochrona częściowa (wg ROZPORZĄDZENIE 2014), CR - krytycznie zagrożone, EN - wymierające, VU - narażone, NT - bliskie zagrożenia, LC - słabo zagrożone, DD - niedostateczne dane (CIEŚLIŃSKI i in. 2006).

\section{WYKAZ GATUNKÓW}

Absconditella lignicola Vězda \& Pišút - na drewnie; stan. 16.

Acrocordia gemmata (Ach.) A. Massal. - na korze Quercus petraea; stan. 13; VU.

Agonimia flabelliformis Halda, Czarnota \& Guz.-Krzem. - na korze Quercus petraea; stan. 6.

Agonimia repleta Czarnota \& Coppins - na korze Quercus petraea; stan. 6.

Anisomeridium polypori (Ellis \& Everh.) M.E. Barr - na korze Alnus glutinosa; stan. 1, 17.

Arthonia mediella Nyl. - na korze Quercus petraea; stan. 12; VU.

Arthonia radiata (Pers.) Ach. - na korze Carpinus betulus; stan. 6.

Arthonia spadicea Leight. - na korze Alnus glutinosa i Quercus petraea; stan. 1, 2, 3, 4, 6, 8, 11, 12, 13, 15, 16, 17, 18, 19, 20.

Arthothelium ruanum (A. Massal.) Körb. - na korze Acer pseudoplatanus i Carpinus betulus; stan. 14, 15, 18; NT.

Bacidina mendax Czarnota \& Guz.-Krzem. - na korze Carpinus betulus oraz na gałązkach Quercus petraea i Salix sp.; stan. 2, 6, 19.

Biatora globulosa (Flörke) Fr. - na korze Quercus petraea; stan. 8.

Buellia griseovirens (Turner \& Borrer ex Sm.) Almb. - na korze Carpinus betulus; stan. 8.

Calicium salicinum Pers. - na korze Quercus petraea; stan. 7; VU.

Candelariella efflorescens R.C. Harris \& W.R. Buck - na korze Salix sp. i na gałązkach Populus tremula; stan. 2, 16.

Chaenotheca chlorella (Ach.) Müll. Arg. - na korze Quercus petraea i na drewnie; stan. 7, 8, 13; CR.

Chaenotheca chrysocephala (Ach.) Th. Fr. - na korze Alnus glutinosa i Quercus petraea; stan. 5, 12, $16,17$.

Chaenotheca ferruginea (Turner ex Sm.) Mig. - na korze Acer pseudoplatanus, Alnus glutinosa, Carpinus betulus, Pinus sylvestris, Quercus petraea i na drewnie; stan. 1, 3, 4, 6, 9, 10, 11, 12, 13, 14, 15, 16, 17, 18, 19, 20.

Chaenotheca furfuracea (L.) Tibell - na korze Alnus glutinosa i Quercus petraea; stan. 1, 4, 7, 8; NT.

Chaenotheca stemonea (Ach.) Müll. Arg. - na korze Quercus petraea; stan. 12; EN.

Chaenotheca trichialis (Ach.) Th. Fr. - na korze Alnus glutinosa, Quercus petraea i na drewnie; stan. $4,6,7,9,11,12,13,15,16,17,18,19,20 ;$ NT.

Chaenotheca xyloxena Nádv. - na drewnie; stan. 19, 20; VU.

Chrysothrix candelaris (L.) J.R. Laundon - na korze Quercus petraea; stan. 7, 8; CR; OS.

Cladonia chlorophaea (Flörke ex Sommerf.) Spreng. - na korze Alnus glutinosa; stan. 3.

Cladonia coniocraea (Flörke) Spreng. - na korze Alnus glutinosa, Betula pendula, Carpinus betulus, Pinus sylvestris, Quercus petraea, Salix sp. i na drewnie; stan. 1, 2, 3, 4, 5, 6, 7, 8, 9, 11, 12, 13, 14, 16, $17,18,19,20$. 
Cladonia digitata (L.) Hoffm. - na Alnus glutinosa, Quercus petraea i na drewnie; stan. 3, 5, 13, 16.

Cladonia fimbriata (L.) Fr. - na drewnie; stan. 2, 16.

Cladonia grayi G. Merr. ex Sandst. - na korze Alnus glutinosa; stan. 1, 16.

Cladonia macilenta Hoffm. - na drewnie; stan. 17.

Coenogonium pineti (Ach.) Lücking \& Lumbsch - na korze Alnus glutinosa, Carpinus betulus, Pinus sylvestris, Quercus petraea i na drewnie; stan. 1, 2, 3, 4, 7, 8, 9, 11, 10, 12, 13, 14, 16, 17, 18, 19.

Evernia prunastri (L.) Ach. - na gałązkach Quercus petraea; stan. 11; NT.

Graphis scripta (L.) Ach. - na korze Carpinus betulus; stan. 6, 8, 10, 11, 14, 15, 18, 19; NT.

Hypocenomyce scalaris (Ach.) M. Choisy - na korze Alnus glutinosa i Quercus petraea; stan. 3, 6, $7,8,9,10,12,16,20$.

Hypogymnia physodes (L.) Nyl. - na korze Alnus glutinosa, Acer pseudoplatanus, Betula pendula, Carpinus betulus, Salix sp., na gałązkach Padus avium i Quercus petraea; stan. 1, 4, 5, 6, 7, 8, 11, 15, $16,18,20$.

Hypogymnia tubulosa (Schaer.) Hav. - na korze Salix sp.; stan. 2; NT; OC.

Lecania naegelii (Hepp) Diederich \& van den Boom - na gałązkach Quercus petraea; stan. 6.

Lecanora argentata (Ach.) Malme - na korze Carpinus betulus; stan. 8.

Lecanora carpinea (L.) Vain. - na korze Carpinus betulus; stan. 6.

Lecanora chlarotera Nyl. - na korze Alnus glutinosa i Salix sp. oraz na gałązach Populus tremula; stan. 16.

Lecanora compallens Herk \& Aptroot - na korze Alnus glutinosa i Carpinus betulus; stan. 2, 16, 18.

Lecanora conizaeoides Nyl. ex Cromb. - na korze Pinus sylvestris; stan. 9.

Lecanora expallens Ach. - na korze Alnus glutinosa, Betula pendula, Carpinus betulus i Quercus petraea; stan. 1, 3, 5, 7, 8, 10, 11, 12, 13, 14, 16, 17.

Lecanora pulicaris (Pers.) Ach. - na korze Alnus glutinosa; stan. 1, 3, 16.

Lecanora symmicta (Ach.) Ach. - na gałązkach Quercus petraea; stan. 6.

Lecidea nylanderi (Anzi) Th. Fr. - na korze Alnus glutinosa; stan. 2.

Lecidella elaeochroma (Ach.) M. Choisy - na korze Carpinus betulus; stan. 19.

Lepra amara (Ach.) Hafellner - na korze Carpinus betulus i Quercus petraea; stan. 12.

Lepraria elobata Tønsberg - na korze Alnus glutinosa i Fagus sylvatica; stan. 1, 3, 7, 16.

Lepraria finkii (B. de Lesd.) R.C. Harris - na korze Alnus glutinosa, Betula pendula, Carpinus betulus i Quercus petraea; stan. 1, 2, 3, 4, 5, 8, 10, 11, 13, 14, 15, 16, 17.

Lepraria incana (L.) Ach. - na korze Alnus glutinosa, Acer pseudoplatanus, Betula pendula, Carpinus betulus, Corylus avellana, Fagus sylvatica, Pinus sylvestris, Quercus petraea, Salix sp. i na drewnie; stan. $1,2,3,4,5,6,7,8,9,10,11,12,13,14,15,16,17,18,19,20$.

Lepraria jackii Tønsberg - na korze Pinus sylvestris; stan. 8.

Lepraria rigidula (B. de Lesd.) Tønsberg - na korze Alnus glutinosa; stan. 17.

Melanelixia glabratula (Lamy) Sandler \& Arup - na korze Alnus glutinosa, Acer pseudoplatanus, Betula pendula, Carpinus betulus, Padus avium, Quercus petraea i Salix sp. stan. 1, 2, 5, 6, 8, 14, 16, 20.

Melanelixia subaurifera (Nyl.) O. Blanco et al. - na gałązkach Quercus petraea; stan. 6; OC.

Melanohalea exasperatula (Nyl.) O. Blanco et al. - na gałązkach Quercus petraea; stan. 4, 6.

Micarea byssacea (Th. Fr.) Czarnota, Guz.-Krzemiń. \& Coppins - na korze Betula pendula; stan. 5.

Micarea micrococca (Körb.) Gams ex Coppins - na korze Alnus glutinosa; 1, 2, 3, 16.

Microcalicium disseminatum (Ach.) Vain. - na korze Quercus petraea; stan. 6, 8.

Opegrapha niveoatra (Borrer) J.R. Laundon - na korze Quercus petraea; stan. 9; VU.

Parmelia serrana A. Crespo, M.C. Molina \& D. Hawksw. - na korze Quercus petraea; stan. 6.

Parmelia sulcata Taylor - na korze Alnus glutinosa, Acer pseudoplatanus, Betula pendula, Carpinus betulus, Quercus petraea, Salix sp. oraz na gałązach Alnus glutinosa, Padus avium i Quercus petraea; stan. 2, 4, 5, 6, 7, 8, 11, 15, 16, 17, 18, 19, 20. 


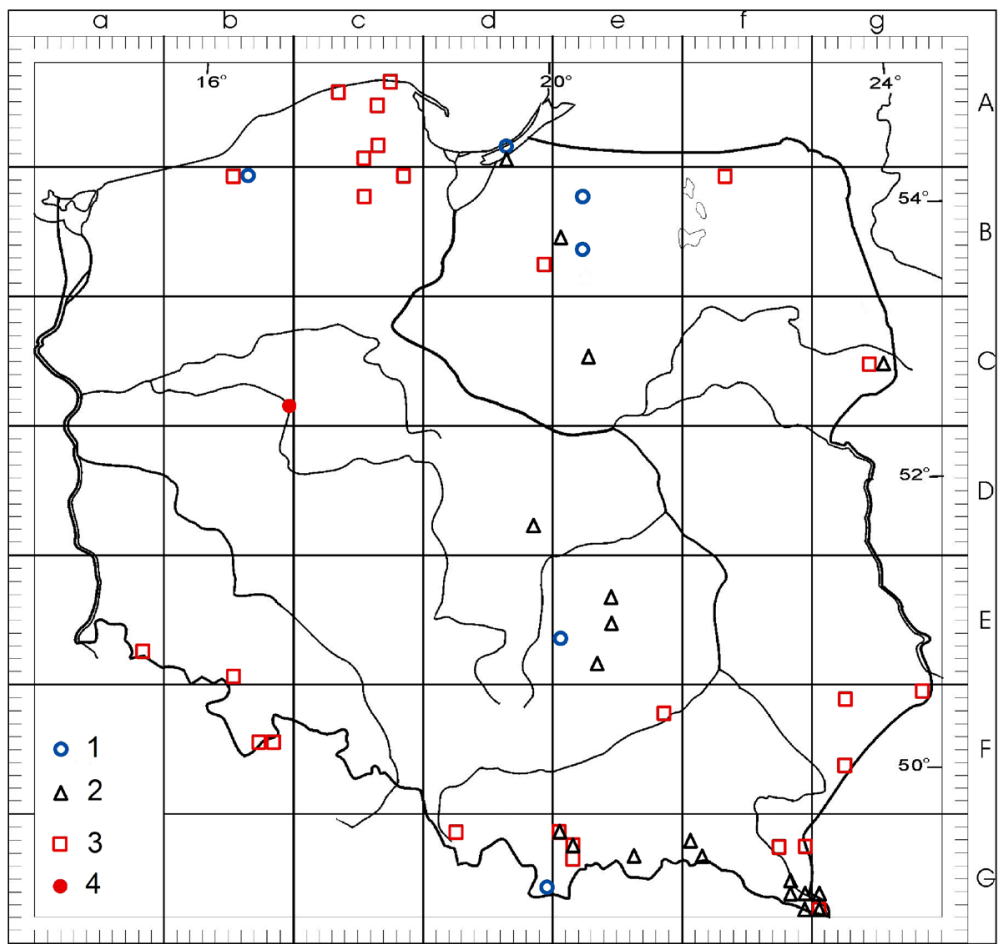

Ryc. 2. Rozmieszczenie stanowisk Agonimia flabelliformis (1), Agonimia repleta (2) i Parmelia serrana (3) w Polsce. 1-3 - znane stanowiska, 4 - nowe stanowiska

Fig. 2. Distribution of Agonimia flabelliformis (1), Agonimia repleta (2) and Parmelia serrana (3) in Poland. 1-3 - known localities, 4 - new localities

Parmeliopsis ambigua (Wulfen) Nyl. - na korze Betula pendula; stan. 5.

Pertusaria coccodes (Ach.) Nyl. - na korze Quercus petraea; stan. 11; NT.

Phaeophyscia orbicularis (Neck.) Moberg - na korze Salix sp, i na gałązkach Populus tremula i Quercus petraea; stan. 2, 3, 6, 16.

Phlyctis argena (Ach.) Flot. - na korze Alnus glutinosa, Acer pseudoplatanus, Carpinus betulus, Corylus avellana, Fagus sylvatica, Padus avium, Quercus petraea i Salix sp.; stan. 1, 2, 5, 6, 7, 8, 9, 10, $12,13,14,15,16,17,18,19$.

Physcia adscendens (Fr.) H. Olivier - na gałązkach Populus tremula i Quercus petraea; stan. 6, 16.

Physcia stellaris (L.) Nyl. - na korze Salix sp. i na gałązkach Populus tremula; stan. 2, 3.

Physcia tenella (Scop.) DC. - na korze Salix sp. i na gałązkach Alnus glutinosa, Populus tremula i Quercus petraea; stan. 1, 2, 3, 4, 6, 8, 15, 16, 18, 19.

Physconia enteroxantha (Nyl.) Poelt - na korze Padus avium; stan. 16.

Placynthiella icmalea (Ach.) Coppins \& P. James - na drewnie; stan. 8, 9, 16.

Platismatia glauca (L.) W.L. Culb. \& C.F. Culb. - na korze Alnus glutinosa, Quercus petraea i Salix sp.; stan. 2, 6 .

Polycauliona polycarpa (Hoffm.) Frödén, Arup \& Søchting - na gałązkach Quercus petraea; stan. 6.

Porina aenea (Wallr.) Zahlbr. - na korze Carpinus betulus i Corylus avellana; stan. 8, 10, 12, 14, 18, 19.

Pseudevernia furfuracea (L.) Zopf - na korze Betula pendula; stan 5. 
Punctelia subrudecta (Nyl.) Krog - na korze Padus avium; stan. 16; VU; OS.

Ramalina farinacea (L.) Ach. - na korze Salix sp.; stan. 2; VU; OC.

Ropalospora viridis (Tønsberg) Tønsberg - na korze Alnus glutinosa, Carpinus betulus i Quercus petraea; stan. 1, 3, 6, 8, 16, 18.

Scoliciosporum chlorococcum (Graeve ex Stenh.) Vězda - na korze Salix sp. i na gałązkach Alnus glutinosa i Populus tremula; stan. 2, 16.

Toniniopsis subincompta (Nyl.) Kistenich, Timdal, Bendiksby \& S. Ekman - na korze Quercus petraea; stan. 19; EN.

Trapeliopsis granulosa (Hoffm.) Lumbsch - na drewnie; stan. 4, 5, 9, 16.

Violella fucata (Stirt.) T. Sprib. - na korze Alnus glutinosa i Salix sp.; stan. 2, 3, 16.

Xanthoria parietina (L.) Th. Fr. - na korze Salix sp. i na gałązkach Populus tremula i Quercus petraea; stan. 2, 3, 6, 15, 16 .

\section{WYNIKI I DYSKUSJA}

W granicach oddziału leśnego 73, Doświadczalnego Nadleśnictwa Zielonka stwierdzono występowanie 81 gatunków porostów. Wśród nich 18 to gatunki znajdujące się na polskiej czerwonej liście porostów (CIEŚLIŃSKI i in. 2006). Pięć taksonów jest objętych ochroną prawną, w tym dwa ochroną ścisłą (Chrysothrix candelaris, Punctelia subrudecta) i trzy ochroną częściową (Hypogymnia tubulosa, Melanelixia subaurifera, Ramalina farinacea), zgodnie z Rozporządzeniem Ministra Środowiska w sprawie dziko występujących gatunków grzybów w Polsce z 2014 r.

Najliczniejszą grupą są gatunki występujące na jednym lub dwóch stanowiskach. Stanowią one $60 \%$ wszystkich obserwowanych taksonów. Tylko jeden gatunek rósł na wszystkich stanowiskach i jest to Lepraria incana. Wysoką frekwencję na badanym terenie osiągnęły również Arthonia spadicea, Chaenotheca ferruginea, Chaenotheca trichialis, Cladonia coniocraea, Coenogonium pineti, Hypogymnia physodes, Lepraria finkii, Parmelia sulcata i Phlyctis argena. Liczba gatunków na poszczególnych stanowiskach jest zbliżona i waha się od 10 do 15. Jedynie na czterech stanowiskach odnotowano więcej niż 20 gatunków. Najbogatszą biotę obserwowano na powierzchni badawczej nr 16. Jest to niewielki fragment łęgu Fraxino-Alnetum, z dominującym drzewostanem powyżej 100 lat (por. Tab. 1), gdzie odnotowano 35 gatunków porostów.

Zróżnicowanie ekologiczne grzybów zlichenizowanych w oddziale 73 jest niewielkie i reprezentowane tylko przez dwie grupy: epifity i epiksyle. Najliczniejszą grupą są gatunki epifityczne, co jest charakterystyczne dla zbiorowisk leśnych użytkowanych gospodarczo. Porosty epiksyliczne są niewielką grupą. Wynika to z małej ilości drewna pozostawionego do zasiedlenia przez grzyby zlichenizowane. Epifity stwierdzono na 11 forofitach (Ryc. 3). Łącznie znaleziono 75 gatunków, które stanowią 92\% całej zbadanej bioty. Najbogatszą listę porostów posiada Quercus petraea. Jest on podstawowym gatunkiem budującym drzewostany w badanych zbiorowiskach leśnych (RUTKOwSKI 2002). Na tym foroficie zarejestrowano 45 gatunków porostów, w tym 19 wyłącznych. Na korze dębów odnaleziono również największą liczbę gatunków zagrożonych (Ryc. 3). Spośród nich na uwagę zasługuje stosunkowo duży udział rzadkich, wyspecjalizowanych przedstawicieli z rodzajów Calicium, Chaenotheca i Microcalicium. To porosty ombrofobowe, unikające 


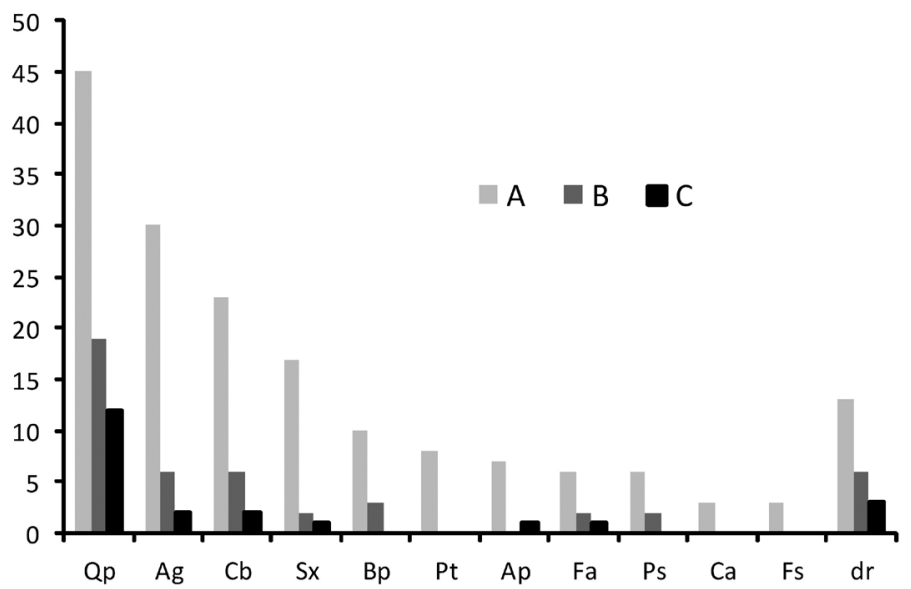

Ryc. 3. Liczba gatunków porostów na poszczególnych rodzajach podłoży: A - łącznie, B - gatunki wyłączne, C - gatunki zagrożone (Qp - Quercus, Ag - Alnus, Cb - Carpinus, Sx - Salix, Bp - Betula, Pt - Populus, Ap - Acer, Fa - Frangula, Ps - Pinus, Ca - Corylus, Fs - Fagus, dr - drewno)

Fig. 3. Number of lichen species recorded on different substrates: A - total, B - exclusive species, C - endangered species (Qp - Quercus, Ag - Alnus, Cb-Carpinus, Sx - Salix, Bp - Betula, Pt - Populus, Ap - Acer, Fa - Frangula, Ps - Pinus, Ca - Corylus, Fs - Fagus, dr - wood)

bezpośredniego dostępu wody opadowej, aerohigrofilne. Występują głównie w głębokich spękaniach kory starych drzew (BARKMAn 1958; Rose 1974; Pedersen 1980; ZalewsKa 2012). Chaenotheca chlorella, Chrysothrix candelaris i Microcalicium disseminatum są również umieszczone na liście wskaźników niżowych lasów puszczańskich (CzYŻEwsKA \& CIEŚLIŃSKI 2003). Na dębach stwierdzono również porosty rzadkie w Polsce, występujące na rozproszonych stanowiskach i nie podawane nigdy wcześniej z terenu Wielkopolski (Ryc. 2). Należą do nich Agonimia flabelliformis, Agonimia repleta i Parmelia serrana.

Pierwszy z nich opisano niedawno jako nowy dla nauki z terenu Czech, Niemiec i Wielkiej Brytanii (Guzow-Krzemińska i in. 2012). W Polsce znaleziony po raz pierwszy w Tatrach (CZARnota 2012). Obecnie jego stanowiska znane są również z Wysoczyzny Polanowskiej (FAŁTYNOwicz i in. 2015), Wysoczyzny Elbląskiej (R. Szymczyk mat. niepubl.), Pojezierza Olsztyńskiego (KubiaK \& SucharzeWSKa 2016) i Wzgórz Łopuszańskich (ŁuBeK 2012a). Gatunek ten wydaje się preferować wilgotne i zacienione miejsca w zbiorowiskach lasów liściastych. Rośnie na mszakach lub korze u podstawy pni i na szyjach korzeniowych, rzadko na glebie, skałach i szczątkach roślin (Guzow-KrzemińsKA i in. 2012). Na badanym terenie stwierdzono go w grądzie, u podstawy pnia potężnego dębu. Drugi takson Agonimia repleta po raz pierwszy odnaleziony został w Gorcach i opisany jako nowy w 2000 r. (CZARNOTA \& COPPINs 2000). Obecnie znany jest głównie z Karpat (CZARNOTA 2000, 2002, 2003, 2012; KISZKA \& KoŚCIELNIAK 2001; BIELCZYK i in. 2016). Jego pojedyncze stanowiska odnotowano również w Górach Świętokrzyskich (ŁUBEK 2012b, 2012c), na Wyżynie KieleckoSandomierskiej (ŁUBEK 2012d), na Wzniesieniach Łódzkich i Wzniesieniach Mławskich (KubiaK \& Szczepkowski 2012; KubiaK 2013), w Puszczy Białowieskiej (Czyżewska i in. 2001), na Pojezierzu Olsztyńskim (KubiaK \& Sucharzewska 2018) i na Wysoczyźnie Elbląskiej (R. Szymczyk mat. niepubl.). Podobnie jak poprzedni gatunek, Agonimia repleta 
preferuje miejsca zacienione i wilgotne. Porasta omszone podstawy pni drzew lub omszone skały (CZARNOTA \& COPPINS 2000). W oddziale 73 porost ten znaleziono na tym samym stanowisku i foroficie co Agonimia flabelliformis, u podstawy pnia starego dębu. Podobny przypadek występowania tych dwóch gatunków razem, zaobserwowano na stanowisku na Wysoczyźnie Elbląskiej i w Tatrach (CzARnota 2012; R. Szymczyk mat. niepubl.).

Parmelia serrana jest gatunkiem, który został wyodrębniony z grupy Parmelia saxatilis s. lato (Molina i in. 2004). Z obszaru Polski po raz pierwszy został podany w $2014 \mathrm{r}$. (OssowsKa i in. 2014). Obecnie jego stanowiska znane są głównie z Wysoczyzny Polanowskiej, Pomorza Gdańskiego, Wzgórz Dylewskich, Pojezierza Ełckiego, Puszczy Białowieskiej, Pogórza Przemyskiego, Roztocza Środkowego, Karpat i Sudetów (FAŁTYNowicz i in. 2015; OssowsKa i in. 2015). Gatunek ten rośnie głównie na drzewach liściastych i iglastych oraz rzadko na omszałych skałach. W Polsce obserwowany prawie wyłącznie na drzewach liściastych w lasach lub na drzewach przydrożnych (Molina i in. 2004; OssowsKa $i$ in. 2014).

Obszar Nadleśnictwa Doświadczalnego Zielonka posiada bogatą dokumentację lichenologiczną. W latach 60. XX w. ukazała się obszerna praca, w której opisano stanowiska 185 gatunków porostów (GLANC 1967). Z oddziału leśnego 73 Glanc podaje 37 gatunków, w tym szereg cennych, jak: Acrocordia gemmata, Calicium salicinum, Chaenotheca brachypoda, Flavoparmelia caperata i Phlyctis agelea. W 1992 r. przeprowadzono ponowne badania w celu wychwycenia zmian zachodzących w biocie porostów (GLANC 1998). Autor wskazuje na problem zanikania porostów na tym terenie. Spośród gatunków stwierdzonych w ramach wcześniejszych badań, nie potwierdza obecności 61, w tym takich jak: Acrocordia gemmata, Chaenotheca chlorella, Ch. chrysocephala, Chrysothrix candelaris, Flavoparmelia caperata, Graphis scripta i Phlyctis agelea.

Problem zanikania gatunków został również zauważony wśród roślin naczyniowych i mszaków (KonATOwSKA \& RUTKOwSKi 2019). Zwiększenie roli drzewostanów sosnowych w gospodarce leśnej w tym na obszarze Puszczy Zielonki (RUTKOwski 2002) oraz ustalony wiek rębny drzewostanów (80-140 lat, według BDL 2020), powodują znaczne zniekształcenie zbiorowisk i ich zubożenie. Na obszarze Nadleśnictwa Doświadczalnego Zielonka zbiorowiska leśne z drzewami powyżej 120 lat, w 1995 r. stanowiły tylko 5\% powierzchni (Glanc 1995). Zmiany zachodzące w szacie roślinnej Puszczy Zielonki (KonatowsKa 2018) pociągają za sobą zmiany w biocie porostów. Istotnym czynnikiem, który kształtuje różnorodność gatunkową porostów w lasach jest ich stopień naturalności i czas trwania drzewostanów (ZALEwSKa 2012; KUbiaK 2013; SzYMCZYK i in. 2015). Rotacja pokoleń drzew dostarcza odpowiednich nisz do życia dla porostów. Obecność sędziwych, żywych drzew, osiągających kres życia i naturalnie obumierających, leżące powalone drzewa w różnym stopniu rozkładu, wykroty przewróconych osobników i stojące lub złamane pnie, stają się miejscem występowania stenotopowych gatunków epifitycznych i epiksylicznych (KoŚCIELNiaK 2008; KubiaK \& SucharZewSKa 2012; ZalewsKa 2012). Bardzo ważnym elementem wpływającym na bogactwo porostów w lasach gospodarczych jest obecność dębów. Posiadają one szeroką skalę ekologiczną oraz długi czas życia osobniczego (KUBIAK 2013). Obecny stan bioty w oddziale 73 jest w znacznym stopniu kształtowany obecnością drzewostanów dębowych w wieku powyżej 150 lat. Stwierdzenie występowania gatunków, 
takich jak Acrocordia gemmata, Chaenotheca chlorella, Ch. chrysocephala, Chrysothrix candelaris i Graphis scripta, które zostały uznane za ginące na terenie Nadleśnictwa Doświadczalnego Zielonka (GLANC 1998), wskazuje na potrzebę ochrony tych drzewostanów. Podobne wnioski o ochronie lasów gospodarczych, z obecnością przestojów starych dębów, prezentują także RutKowski i KuKwa (2000), KubiaK (2013), KubiaK i SuchaRZEWSKA (2018).

\section{PODSUMOWANIE}

Badany teren oddziału leśnego 73 stanowi niewielki fragment Nadleśnictwa Doświadczalnego Zielonka (40 ha, 1\% powierzchni zalesionej). Na analizowanym obszarze stwierdzono występowanie 81 gatunków grzybów zlichenizowanych. W świetle dotychczasowych badań biota oddziału 73 jest bogata i zróżnicowana. Rezultat prezentowanych badań można porównać z pracami, które obejmują znacznie większe powierzchniowo tereny, a uzyskane tam wyniki są zbliżone pod względem liczby odnalezionych gatunków grzybów zlichenizowanych (STOLARCZyK 2003; SzCZEPAŃSKa 2010; KubiaK 2013; ZANiEWSKi i in. 2015; KubiaK \& SuCHARZEWSKA 2018). Obecność drzew w wieku powyżej 150 lat sprzyja występowaniu cennych gatunków porostów, wrażliwych na zmiany warunków siedliskowych, zwłaszcza wilgotności względnej powietrza. Są to przede wszystkim porosty - wskaźniki niżowych lasów puszczańskich oraz taksony zagrożone w Polsce (CZYŻEWSKA \& CIEŚLIŃsKi 2003; CIEŚLIŃSKI i in. 2006). Dłuższe wyłączenie z gospodarki leśnej oddziału 73 (około 50 lat) umożliwiło zachowanie tego cennego fragmentu lasu, który stanowi wartościowe refugium lokalnej różnorodności gatunkowej. Ze względu na ograniczony zakres przeprowadzonych obserwacji, uzasadnione jest kontynuowanie badań lichenologicznych na obszarze Nadleśnictwa Doświadczalnego Zielonka.

Podziękowania. Autorzy serdecznie dziękują dr Emilii Ossowskiej (Gdańsk) i prof. Pawłowi Czarnocie (Rzeszów) za sprawdzenie części oznaczeń. Ponadto dziękują dr. Agnieszce Kowalewskiej (Gdańsk) za krytyczne przeczytanie tekstu i uwagi oraz prof. Martinowi Kukwie (Gdańsk) za wskazówki dotyczące nomenklatury lichenologicznej. Autorzy składają również podziękowania anonimowym recenzentom za wszelkie uwagi.

\section{LITERATURA}

Barkman J. J. 1958. Phytosociology and ecology of cryptogamic epiphytes. s. xiii + 628. J. J. Barkman Van Gorcum \& Company, Assen, Netherlands.

BDL. 2020. Bank Danych o Lasach. https://www.bdl.lasy.gov.pl/portal/mapy (dostęp: 20.04.2020).

Bielczyk U., Czarnota P., Kukwa M., Śliwa L., Kościelniak R., Betleja L., Kozik R., Krzewicka B., Hachulka M., Adamska E., Węgrzyn M., Bielec D., Flakus A., Guzow-Krzemińska B., Kolanko K., Kozik J., LeŚniański G., Lisowska M., Oset M., Osyczka P., Pietrzykowska-Urban K., SadowskaDeś A., SŁaby A., Studzińska-Sroka E., Wilk K., Zaniewski P. T. \& Zarabska-Bożejewicz D. 2016. Lichens and lichenicolous fungi of Magurski National Park (Poland, Western Carpathians). - Polish Botanical Journal 61(1): 127-160.

BULiGL. 2014. Plan urządzenia lasu Nadleśnictwa Doświadczalnego Zielonka na okres od 1 stycznia 2014 r. do 31 grudnia 2023 r. Mskr. Nadleśnictwo Doświadczalne Zielonka, Murowana Goślina. 
Cieśliński S., CZyŻewska K. \& FABISZewski J. 2006. Red list of the lichens in Poland. - W: Z. MireK, K. Zarzycki, W. Wojewoda \& Z. Szeląg (red.). Red list of plants and fungi in Poland, s. 71-89. W. Szafer Institute of Botany, Polish Academy of Sciences, Kraków.

Czarnota P. 2000. Porosty Gorczańskiego Parku Narodowego. Cześć I. Wykaz i rozmieszczenie gatunków. - Parki Narodowe i Rezerwaty Przyrody 19(1): 3-73.

CZarnota P. 2002. Flora porostów rezerwatu „Żebracze” w Beskidzie Sądeckim. - Parki Narodowe i Rezerwaty Przyrody 21(4): 385-410.

Czarnota P. 2003. Notes on some new and noteworthy lichens from southern Poland. - Graphis Scripta 14: $18-26$.

Czarnota P. 2007. The lichen genus Micarea (Lecanorales, Ascomycota) in Poland. - Polish Botanical Studies 23: 1-199.

CZARnota P. 2012. New records of lichenized and lichenicolous fungi from Tatra National Park (W Carpathian). - W: L. LIPNICKI (red.), Lichen protection - Protected lichen species, s. 287-300. Sonar Literacki, Gorzów Wielkopolski.

Czarnota P. \& Coppins B. J. 2000. A new species of Agonimia and some interesting lichens from Gorce Mts (Western Beskidy Mts) new to Poland. - Graphis Scripta 11: 56-60.

CZARnota P. \& GuZow-KrzemińsKa B. 2018. Bacidina mendax sp. nov., a new widespread species in Central Europe, together with a new combination within the genus Bacidina. - The Lichenologist 50(1): 43-57.

CZYŻEwska K. \& CiEŚLIŃski S. 2003. Porosty - wskaźniki niżowych lasów puszczańskich w Polsce. - Monographiae Botanicae 91: 223-239.

Czyżewska K., Motiejūnaitė J. \& Cieśliński S. 2001. Species of lichenized and allied fungi new to Białowieża Large Forest (NE Poland). - Acta Mycologica 36(1): 13-19.

Dziabaszewski B. 1959. Z badań nad porostami Dziewiczej Góry pod Poznaniem. - Przyroda Polski Zachodniej 3(1-2): 190.

Dziabaszewski B. 1962. Porosty okolic Poznania na tle porostów Wielkopolski. - Prace Komisji Biologicznej Poznańskiego Towarzystwa Przyjaciół Nauk 22(4): 1-159.

Faetynowicz W. \& Kossowska M. 2016. The lichens of Poland. A fourth checklist. - Acta Botanica Silesiaca, Monographiae 8: 3-122.

FaŁtynowicz W., Kowalewska A., Szymczyk R., Kukwa M., Adamska E., Czarnota P., Kubiak D. \& PietrzykowsKa-Urban K. 2015. Lichen diversity in the managed forests of the Karnieszewice Forest Division and its surroundings (N Poland). - Ecogical Questions 22: 55-66.

GLanc K. 1956. Zielnik porostów Doświadczalnego Nadleśnictwa Zielonka pod Poznaniem. s. 11. Zakład Botaniki Leśnej Wyższej Szkoły Rolniczej, Poznań.

GLanc K. 1957. Zielnik porostów Doświadczalnego Nadleśnictwa Zielonka pod Poznaniem. Cz. II, nr 26-50. s. 9. Zakład Botaniki Leśnej Wyższej Szkoły Rolniczej, Poznań.

Glanc K. 1961. Zielnik porostów Doświadczalnego Nadleśnictwa Zielonka pod Poznaniem. Cz. III, nr 51-75. s. 11. Zakład Botaniki Leśnej Wyższej Szkoły Rolniczej, Poznań.

GLANC K. 1965. Ugrupowania porostów epifitycznych w zespołach leśnych Nadleśnictwa Doświadczalnego Zielonka pod Poznaniem. - Prace Komisji Biologicznej Poznańskiego Towarzystwa Przyjaciół Nauk 24(4): 1-59.

GLANC K. 1967. Flora porostów i jej udział w zespołach leśnych nadleśnictwa doświadczalnego Zielonka pod Poznaniem. - Rocznik Wyższej Szkoły Rolniczej w Poznaniu 34(8): 137-182.

GLANC K. 1995. Stan zbiorowisk epifitycznych porostów stwierdzonych w roku 1962 i 1963 na pniach sosny zwyczajnej (Pinus sylvestris L.) w lasach Nadleśnictwa Doświadczalnego Zielonka pod Poznaniem. 
- Prace Komisji Nauk Rolniczych i Komisji Nauk Leśnych, Poznańskie Towarzystwo Przyjaciół Nauk 80: $49-56$.

GLanc K. 1998. Zanikanie porostów na obszarze Puszczy Zielonka pod Poznaniem (Wielkopolska). - W: K. CzYŻĖwska (red.), Różnorodność biologiczna porostów, s. 71-79. Wydawnictwo Uniwersytetu Łódzkiego, Łódź.

Guzow-Krzemińska B., Halada J. P. \& Czarnota P. 2012. A new Agonimia with flabelliform thallus from Europe. - The Lichenologist 44(1): 1-12.

HAFELLNER J. \& TÜRK R. 2016. The lichenized fungi of Austria - a new checklist of the taxa so far recorded, with data to distribution and substrate ecology. - Stapfia 104(1): 1-216.

JabŁońSKa A. 2012. The lichen genus Porpidia Körb. in Poland. - Monographiae Botanicae 102: 5-123.

Kistenich S., Timdal E., Bendiksby M. \& Ekman S. 2018. Molecular systematics and character evolution in the lichen family Ramalinaceae (Ascomycota: Lecanorales). - Taxon 67(5): 871-904.

Kiszka J. \& KościelniaK R. 2001. Nowe i rzadkie gatunki porostów (Lichenes) w Bieszczadzkim Parku Narodowym i jego otulinie. Część III. - Roczniki Bieszczadzkie 9: 27-32.

Konatowska M. 2018. Porównanie zbiorowisk roślinnych w Nadleśnictwie Doświadczalnym Zielonka z połowy XX i początku XXI wieku. s. iii + 586. Mskr. pracy doktorskiej, Katedra Siedliskoznawstwa i Ekologii Lasu Uniwersytetu Przyrodniczego w Poznaniu.

Konatowska M. \& RutKowski P. 2011. Nadleśnictwo Doświadczalne Zielonka na tle źródeł historycznych. - Studia i Materiały Ośrodka Kultury Leśnej 10: 63-70.

Konatowska M. \& RutKowski P. 2019. Phytosociology - a useful tool for the assessment of past and future human impacts on plants and forest ecosystems. - Journal of Biosciences and Medicines 7: $154-163$.

KONDRACKI J. 2009. Geografia regionalna Polski. Wyd. 3. s. 440. Wydawnictwo Naukowe PWN, Warszawa.

Kowalewska A., Kukwa M., Ostrowska I., JabŁońska A., Oset M. \& SzoK J. 2008. The lichens of the Cladonia pyxidata-chlorophaea group and allied species in Poland. - Herzogia 21: 61-78.

KoŚCIELNIAK R. 2008. Znaczenie lasów o charakterze pierwotnym i naturalnym dla zachowania różnorodności gatunkowej porostów w Bieszczadach. - Roczniki Bieszczadzkie 16: 67-76.

KRAwIEC F. 1934. Flora epifityczna lasów bukowych Wielkopolski. - Acta Societatis Botanicorum Poloniae 11: 317-327.

Krawiec F. 1935. Lichenotheca Polonica. Fasc. II. Lichenes Posnanienses (51-100). - Instytut Botaniczny Uniwersytetu Poznańskiego, Poznań, 1-10.

KRAwIEC F. 1938. Flora epilityczna głazów narzutowych zachodniej Polski. - Prace Komisji MatematycznoPrzyrodniczej Poznańskiego Towarzystwa Przyjaciół Nauk, Seria B Nauki Biologiczne 9(2): 1-254.

KubiaK D. 2013. Znaczenie starodrzewu dla zachowania różnorodności porostów w lasach na przykładzie pozostałości Puszczy Mazowieckiej. - Leśne Prace Badawcze 74(3): 245-255.

Kubiak D. \& Kukwa M. 2011. Chromatografia cienkowarstwowa (TLC) w lichenologii. - W: M. DynowSKA \& E. EJDYS (red.), Mikologia laboratoryjna. Przygotowanie materiału badawczego i diagnostyka, s. 176-190. Wydawnictwo Uniwersytetu Warmińsko-Mazurskiego, Olsztyn.

Kubiak D. \& Sucharzewska E. 2012. Porosty - wskaźniki niżowych lasów puszczańskich w zespołach leśnych rezerwatu „Las Warmiński” (Nadleśnictwo Nowe Ramuki). - Sylwan 156(8): 627-636.

Kubiak D. \& SucharzewsKa E. 2016. New and interesting lichen records from northeastern Poland. - Acta Mycologica 51(1): 1073.

Kubiak D. \& Sucharzewska E. 2018. Porosty epifityczne starodrzewów dębowych w nadleśnictwie Stare Jabłonki. - Chrońmy Przyrodę Ojczystą 74(1): 27-36. 
KUbiak D. \& SzcZEPKowsKi A. 2012. Porosty Lasów Rogowskich SGGW (3): rezerwat „Doliska”, zespół przyrodniczo-krajobrazowy „Dolina Mrogi” i uroczysko „Gutkowice” - Studia i Materiały Centrum Edukacji Przyrodniczo-Leśnej w Rogowie 14(32): 190-204.

Kukwa M. 2006. The lichen genus Lepraria in Poland. - Lichenologist 38(4): 293-305.

Kukwa M. 2011. The lichen genus Ochrolechia in Europe. s. 309. Fundacja Rozwoju Uniwersytetu Gdańskiego, Gdańsk.

ŁubeK A. 2012a. Agonimia species and other rare lichens in Central Poland. - Acta Mycologica 47(2): 203-212.

ŁubEK A. 2012b. The lichen biota of "Skałki Piekło pod Niekłaniem" nature reserve - current state and changes in species composition over the past 100 years. - Polish Journal of Natural Sciences 27(2): $135-150$.

ŁUBEK A. 2012c. Nowe dane o interesujących gatunkach porostów z Gór Świętokrzyskich i terenów przyległych. - Fragmenta Floristica et Geobotanica Polonica 19(1): 125-135.

ŁuBEK A. 2012d. The condition of lichen biota in "Świnia Góra" nature reserve (Kielecko-Sandomierska Upland). - W: L. LIPNICKI (red.), Lichen protection - Protected lichen species, s. 221-232. Sonar Literacki, Gorzów Wielkopolski.

Molina M. C., Crespo A., Blanco O., Lumbsch H. T. \& Hawksworth D. L. 2004. Phylogenetic relationships and species concepts in Parmelia s. str. (Parmeliaceae) inferred from nuclear ITS rDNA and $\beta$-tubulin sequences. - Lichenologist 36(1): 37-54.

NADLEŚNICTWO 2020. http://www1.up.poznan.pl/lzdmg/content/nadle\%C5\%9Bnictwo (dostęp: 12.01.2020).

Nowaczyk Cz. 1955. Zielnik mchów Doświadczalnego Nadleśnictwa Zielonka pod Poznaniem. s. 15. Zakład Botaniki Leśnej Wyższej Szkoły Rolniczej w Poznaniu, Poznań.

NowaczyK Cz. 1959. Mszaki Doświadczalnego Nadleśnictwa Zielonka pod Poznaniem. - Roczniki Wyższej Szkoły Rolniczej w Poznaniu 7: 137-157.

NowaCzYK Cz. 1960. Rzadsze rośliny naczyniowe znalezione w Doświadczalnym Nadleśnictwie Zielonka pod Poznaniem. - Badania Fizjograficzne nad Polską Zachodnią 6: 285-288.

Nowaczyk Cz. 1964. Zespoły leśne doświadczalnego Nadleśnictwa Zielonka pod Poznaniem. - Prace Komisji Nauk Rolniczych i Komisji Nauk Leśnych Poznańskiego Towarzystwa Przyjaciół Nauk 17(2): 213-271.

Orange A., James P. W. \& White F. J. 2001. Microchemical methods of the identification of lichens. s. 101. British Lichen Society, London.

Ossowska E., SzcZePańska K. \& Kossowska M. 2015. New records of Parmelia ernstiae and P. serrana (Ascomycota, Parmeliaceae) in Poland. - Acta Mycologica 50(2): 1065.

Ossowska E., Szymczyk R., Bohdan A. \& Kunwa M. 2014. The lichen family Parmeliaceae in Poland. III. Parmelia serrana, new to Poland. - Acta Societatis Botanicorum Poloniae 83(1): 81-84.

Pedersen I. 1980. Epiphytic lichen vegetation in an old oak wood Kaas Skov. - Svensk Botanisk Tidsskrift 75: $105-120$.

Ratyńska H., Lewandowska A., Waldon-Rudzionek B. \& Mazur M. 2015. Species share of MolinioArrhenatheretea class in vegetation of the Forest Arboretum in Zielonka near Poznań and in adjacent treestands. - Steciana 19(4): 245-253.

Rose F. 1974. The epiphytes of oak. - W: M. G. Morris \& F. H. Perring (red.), The British oak: its history and natural history. - Botanical Society of the British Isles, Conference Reports (Faringdon) 14: $250-273$.

RoZPORZĄDZENIE Ministra Środowiska z dnia 9 października 2014 r. w sprawie ochrony gatunkowej grzybów (Dz. U. nr 0, poz. 1408). 
RUTKOwSKI P. 2002. Operat typów siedliskowych lasu, roślinności rzeczywistej i potencjalnej Nadleśnictwa Doświadczalnego Zielonka. s. 152. Mskr. Nadleśnictwo Doświadczalne Zielonka, Murowana Goślina.

RutKowski P. \& KuKwa M. 2000: Materiały do poznania porostów epifitycznych dębów i buków w północnej Polsce. - Badania Fizjograficzne nad Polską Zachodnią, Seria B - Botanika 49: 207-215.

RUTKOwSKi P. \& ŚMIgIELSKA-WoJTYNIAK L. 2008. Wpływ tworzenia sztucznych zbiorników wodnych na przylegające drzewostany na przykładzie żwirowni w Owińskach (Nadleśnictwo Doświadczalne Zielonka). - Studia i Materiały Centrum Edukacji Przyrodniczo-Leśnej w Rogowie 10(2): 260-275.

Rutkowski P., Konatowska M. \& Wajsowicz T. 2019. Tree-soil-water relationships in European black alder forest - Case study. - Mechanization in Agriculture \& Conserving of the Resources 65: 200-203.

StolarczyK P. 2003. Porosty Wiśnicko-Lipnickiego Parku Krajobrazowego na Pogórzu Wiśnickim. - Fragmenta Floristica et Geobotanica Polonica 10: 125-135.

SZCZEPAŃSKA K. 2010. Porosty Gryżyńskiego Parku Krajobrazowego. - Acta Botanica Silesiaca 5: 167-174.

SZYMCZYK R., SZYDŁowsKa J. \& ZALEWSKA A. 2015. Wpływ stanu zachowania zbiorowisk leśnych na cenne gatunki porostów na przykładzie wybranych rezerwatów Wysoczyzny Elbląskiej. - Studia i Materiały Centrum Edukacji Przyrodniczo-Leśnej w Rogowie 17(44): 59-70.

Turczański K., Rutkowski P., Dyderski M., K., Wrońska-Pilarek D. \& Nowiński M. 2020. Soil pH and organic matter content affects European ash (Fraxinus excelsior L.) crown defoliation and its impact on understory vegetation. - Forests 11(1): 1-15.

WieczoreK A. 2018. The lichen genus Opegrapha s. 1. in Poland: morphological variability, ecology, and distribution. - Monographiae Botanicae 107: 7-162.

Zalewska A. 2012. Ecology of Lichens of the Puszcza Borecka Forest (NE Poland). s. 458. W. Szafer Institute of Botany, Polish Academy of Sciences, Kraków.

Zaniewski P. T., Topolska K., Kozub Ł., Dembicz I. \& Wierzbicka M. 2015. Rezerwat przyrody Puszcza Słupecka jako przykład młodego lasu o wysokim bogactwie gatunkowym porostów. - Studia i Materiały Centrum Edukacji Przyrodniczo-Leśnej w Rogowie 17(44): 84-95.

Zielony R. \& Kliczkowska A. 2012. Regionalizacja przyrodniczo-leśna Polski 2010. s. 356. Centrum Informacyjne Lasów Państwowych, Warszawa.

\section{SUMMARY}

This paper presents the results of lichenological studies conducted in forest section 73 of the Zielonka Experimental Forest Division in 2019. Species were searched at 20 research sites (Fig. 1). This area is covered almost exclusively by oak-hornbeam woods Galio sylvatici-Carpinetum betuli. In depressions there are small areas of boggy alder forest Ribeso nigri-Alnetum and ash-alder forest Fraxino-Alnetum (Tab. 1).

The objective was to investigate the species diversity and habitat preferences of the lichens. The lichen biota of the study area is rich and diverse: 81 species were found. Epiphytes constitute the most important ecological group of the analysed biota. Representatives of this group were found on 11 phorophytes. The richest epiphytic lichen biota was recorded on Quercus petraea, Alnus glutinosa and Carpinus betulus (Fig. 3). Five of the identified taxa are protected (Chrysothrix candelaris, Hypogymnia tubulosa, Melanelixia subaurifera, Punctelia subrudecta, Ramalina farinacea) and 18 are red-listed in Poland (CIEŚLIŃSKI et al. 2006). The most valuable are Acrocordia gemmata, Arthonia mediella, Chaenotheca chlorella, Ch. stemonea and Toniniopsis subincompta. Agonimia flabelliformis, A. repleta, Bacidina mendax and Parmelia serrana were found in Wielkopolska Province for the first time (Fig. 2). The biota also includes species that are rare or rarely recorded in Poland: Anisomeridium polypori, Arthonia radiata, Calicium salicinum, Micarea byssacea and Microcalicium disseminatum.

Wptynęto: 02.02.2020 r.; przyjęto do druku: 07.09.2020 r. 